\title{
PENERAPAN METODE PENGEMBANGAN WATERFALL UNTUK APLIKASI PENDATAAN DAN UANG KAS MAKAM
}

\author{
Suci Safina Suhasana ${ }^{1}$, Gilang Ryan Fernandes ${ }^{2}$, Iwan Budiarso ${ }^{3}$ \\ 1,2,3 Universitas Indraprasta PGRI \\ Jalan Raya Tengah No 80, Kelurahan Gedong, Pasar Rebo, Jakarta Timur \\ ${ }^{1}$ sucisafina@gmail.com, ${ }^{2}$ gilang.fernandes@gmail.com, ${ }^{3}$ budiarso.iwan@gmail.com
}

\begin{abstract}
ABSTRAK
Pesatnya perkembangan Informatika di era modern sekarang menjadikan Informatika bagian utama dari kehidupan, termasuk di lembaga pemerintah atau swasta, karena sistem memusatkan dan mengontrol semua bagian lembaga. Mengingat perkembangan teknologi yang terus menjadi pesat, juga bermanfaat sebagai media alternatif dalam memudahkan pendataan dan uang kas makam. Tujuan dari perancangan sistem informasi ini adalah menganti sistem lama dalam mengelola pendataan makam dan uang kas menjadi sistem baru yang sudah terkomputerisasi dengan baik sehingga menjadi sistem informasi yang efisien, mempermudah dalam mengelola dan memproses data yang dibutuhkan menjadi lebih cepat dan tepat setiap digunakan. Dengan adanya sistem informasi dapat menyediakan informasi secara akurat dan terjaga keamanan user. Metode penelitian disini menggunakan metode kualitatif, sedangkan dalam metode pengembangan menggunakan metode Waterfall. Hasil dari penelitian ini yaitu mempermudah pendataan makam dan uang kas yang memerlukan kecepatan dan ketepatan informasi.
\end{abstract}

Kata Kunci: Aplikasi Pendataan, Uang Kas, Waterfall.

\begin{abstract}
The rapid progress of informatics in the modern era now makes informatics a major part of life, including in government or private institutions, because the system centralizes and controls all parts of the institution. Given the rapid development of technology, it is also useful as an alternative media in facilitating data collection and grave cash. The purpose of designing this information system is to replace the old system in managing data collection on graves and cash into a new system that is well computerized so that it becomes an efficient information system, making it easier to manage and process the data needed to be faster and more precise every time it is used. With the information system can provide information accurately and user security is maintained. The research method here uses qualitative methods, while the development method uses the Waterfall method. The results of this study are to facilitate data collection of graves and cash which requires speed and accuracy of information.
\end{abstract}

Key Word: Data Collection Application, Cash, Waterfall

\section{PENDAHULUAN}

Suatu sistem dikatakan baik jika sistem tersebut memadai dan implementasinya tidak menyimpang. Penerapan sistem yang terus menerus menyimpang dapat mengganggu kegiatan operasional dan merusak kegunaan sistem itu sendiri.

Menurut Sutabri (2012: 38) "Sistem informasi adalah sistem yang ada dalam organisasi dimana kebutuhan pengolahan transaksi setiap hari yang menunjang operasi organisasi manajerial dengan kegiatan strategis suatu organisasi dengan tujuan menyediakan kepada pihak luar tertentu dengan laporan yang dibutuhkan".
Makam menurut bahasa maksudnya kubur alias pekuburan. Sebaliknya pemakaman merupakan tempat mengubur. Pada saat membicarakan makam pastinya tidak terlepas dengan persoalan

kematian sebab kematian merupakan suatu yang pasti, kematian merupakan suatu yang tidak bisa dihindari, kematian merupakan suatu yang tiap makhluk tentu hadapi. Allah SWT berfirman:

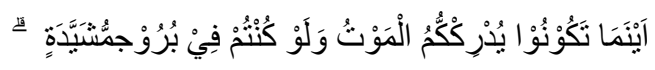

Artinya : "Dimana saja kamu berada, kematian akan mendapatkan kamu, kendatipun kamu di dalam benteng yang tinggi lagi kokoh". (Q.S. An Nisa : 78) 
Berdasarkan uraian singkat di atas, untuk memecahkan permasalahan yang dihadapi, penulis memanfaatkan teknologi komputer dengan membuat perancangan sistem informasi, yang diharapkan dengan terdapatnya sistem informasi ini dapat memberikan kemudahan dalam memproses data untuk mendapatkan informasi yang diinginkan sehingga teknologi informasi semakin berpengaruh peranannya sebagai sarana penunjang pembangunan serta memberikan cara pandang baru kepada masyarakat tentang pemanfaatan IT.

Menurut Romney \& Steinbart (2015: 3) "Sistem adalah suatu rangkaian dari dua maupun lebih dari komponen-komponen yang saling berhubungan dan yang berinteraksi untuk mencapai sebuah tujuan. Sebagian besar sistem terdiri dari subsistem yang lebih kecil dan yang menunjang sistem yang lebih besar".

Menurut Sutabri (2012: 6) "Informasi adalah suatu data yang telah diklasifikasikan atau dikelola maupun diinterpretasikan untuk digunakan kedalam proses pengambilan sebuah keputusan".

Menurut Raharjana (2017: 73) "Sistem informasi merupakan kesatuan banyak elemen yang saling tersambung untuk mengumpulkan (input), memanipulasi (proses), menyimpan, serta mendistribusikan (output) data maupun informasi dan menyebabkan respon (mekanisme feedback) untuk memenuhi suatu tujuan".

Menurut Irwansyah \& Moniaga (2014: 240) "Data Flow Diagram atau DFD merupakan alat yang menunjukkan alur data pada sistem dalam bentuk grafik. Elemen berarti bagi DFD adalah alur data, proses, penyimpanan data serta sumber data".

Menurut Sukamto \& Shalahuddin (2015: 80) "Entitiy Relationship Diagram (ERD) adalah pemodelan awal basis data yang akan dikembangkan berdasarkan teori himpunan dalam bidang matematika untuk pemodelan basis data relasional".

Menurut Yuliani (2018: 15) "Metode yang lain dimulai dengan Entity Relationship Diagram dan langsung dikonversikan ke LRS”.
Menurut Hasugian \& Shidiq (2012: 608) "Logical Record Structure (LRS) adalah sebuah model sistem yang digambarkan oleh diagram-ER kemudian akan mengikuti pola atau aturan pemodelan spesifik dalam kaitannya dengan konvensi ke LRS".

Menurut Sukamto \& Shalahuddin (2015: 73) "Kamus data adalah kumpulan daftar elemen data yang mengalir pada sistem perangkat lunak sehingga masukan (input) dan keluaran (output) dapat difahami secara umum".

\section{METODE PENELITIAN}

Dalam melakukan penelitian senantiasa diperlukan suatu metode penelitian yang sesuai dengan pokok permasalahan yang akan diteliti. Metode penelitian yang digunakan oleh penulis dalam penulisan tugas akhir ini adalah metode penelitian kualitatif.

Menurut Djam'an Satori (2011: 23) “Metode Penelitan Kualitatif adalah sebuah penelitian yang dilakukan karena peneliti ingin mendalami fenomena ini tidak dapat diukur secara deskriptif sebagai suatu proses langkah kerja".

Dalam pengembangan sistem informasi pendataan makam dan uang kas, metode yang akan digunakan yaitu metode waterfall, metode waterfall biasa di sebut dengan air terjun yang berarti model yang dikembangkan untuk mengembangan perangkat lunak, membuat perangkat lunak, model berkembang secara sistematis dari satu tahap ke tahap lain dalam metode seperti air terjun.

Menurut Fernandes dan Lina (2021: 775) "Model ini menganjurkan suatu pendekatan kepada pengembangan aplikasi yang sistematik serta sekuensial yang diawali dari tingkatan kemajuan sistem dari segala analisis, desain, kode, pengujian serta pemeliharaan".

Tahap-tahap dalam sebuah pengembangan model waterfall adalah sebagai berikut: 


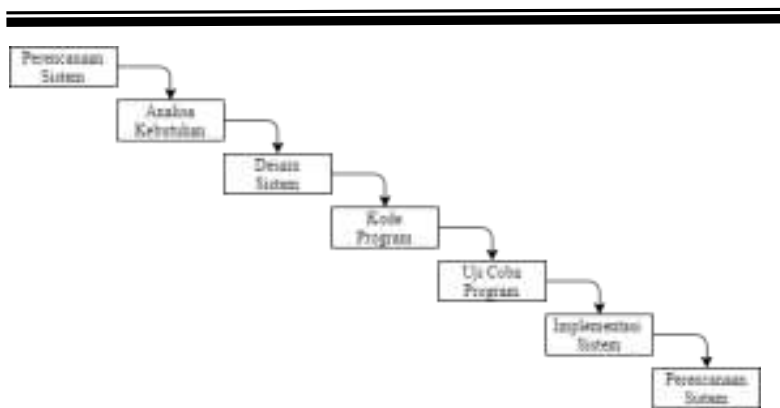

Gambar 1. Metode Waterfall

Tahapan dalam langkah-langkah pengembangan sistem penelitian ini meliputi:

1. Perancangan Sistem

Pada tahap ini pemimpin proyek akan memenuhi persyaratan dalam sebuah proyek. Ini menghitung tenaga kerja dan bahan yang dibutuhkan, membuat jadwal dengan tujuan, menetapkan tim dan struktur kepemimpinan untuk proyek tersebut.

2. Analisa Kebutuhan

Langkah ini ialah analisa terhadap kebutuhan sistem. Pengumpulan informasi dalam sesi ini dapat melaksanakan suatu riset, wawancara ataupun riset literature.

3. Desain Sistem

Tahapan dimana dicoba penuangan benak serta perancangan sistem terhadap pemecahan dari kasus yang terdapat dengan memakai fiturpemodelan sistem semacam DFD (Data Flow Diagram), diagram ikatan ERD (Entity Relationship Diagram) dan struktur serta bahasan informasi.

4. Penyusunan Kode Program

Penyusunan kode program ataupun coding ialah penerjemahan design dalam bahasa yang dapat dikenali oleh PC. Dicoba oleh programmer yang hendak menterjemahkan transaksi yang dimohon oleh user.

5. Pengujian Program

Tahapan akhir dimana sistem yang baru diuji keahlian serta keefektifannya sehingga didapatkan kekurangan serta kelemahan sistem yang setelah itu dicoba pengkajian ulang serta revisi terhadap aplikasi jadi lebih baik serta sempurna.

6. Implementasi Sistem

Tahapan implementasi merupakan tahapan dimana semua elemen dan aktivitas sistem disatukan dengan langkah-langkah.

7. Pelaksanaan Program serta Pemeliharaan

Fitur lunak yang telah di informasikan kepada pelanggan tentu hendak hadapi pergantian. Pergantian tersebut dapat sebab hadapi kesalahan sebab fitur lunak wajib membiasakan dengan area baru, ataupun sebab pelanggan

fungsional.

\section{HASIL DAN PEMBAHASAN}

Dari hasil penelitian yang dilakukan maka penulis dapat menganalisa permasalahan yang ada pada Makam Syeh Maulana Maghribi, yaitu:

1. Sulitnya membuat data anggota dan kegiatan yang mencangkup pendataan anggota, kegiatan, dan pembayaran karena sering terjadi kehilangan berkas-berkas dan tempat penyimpanan kurang memadai sehingga sulitnya dalam proses pengambilan keputusan oleh Makam Syeh Maulana Maghribi.

2. Dalam pemasukan dan pengeluaran uang sering terjadi kesalahan menghitung dan kurang keakuratan dalam perhitungan sehingga dapat menimbulkan kekeliruan dalam pengolahan manajemen makam.

Mencari alternatif penyelesaian masalah sangat dibutuhkan guna membangun operasional Perancangan Sistem Informasi Pendataan Makam dan Uang Kas yang efektif pada Makam Syeh Maulana Maghribi agar dapat meningkatkan perkembangan ke arah yang lebih baik lagi dari sebelumnya.

Berikut uraian dari penyelesaian masalah yang diharapkan dari permasalahan di atas:

1. Diperlukan adanya suatu sistem yang terkomputerisasi dan dapat mengganti sistem lama untuk pendataan makam dan uang kas agar dapat mempermudah pekerjaan, tidak memerlukan banyak waktu dan tenaga dalam pembuatan laporan yang diserahkan kepada Makam Syeh Maulana Maghribi, dan pembayaran bisa dibuat kapan saja jika diperlukan.

2. Dengan adanya sistem yang terkomputerisasi diharapkan dapat meminimalisasi kesalahan perhitungan dan kurang keakuratan yang terjadi pada sistem lama.

Aturan bisnis yang diusulkan sebagai berikut:

1. Pengurus mengisi form Pengurus.

2. Pengurus mengisi form Anggota.

3. Pengurus mengisi form Makam.

4. Setelah itu Pengurus menerima data identitas Pengurus, Anggota, dan Makam

5. Pihak makam mengadakan kegiatan beserta rincian biayanya.

6. Pengurus mendata anggota yang akan membayar uang kas.

7. Pengurus memberikan tagihan uang kas berdasarkan data pembukuan anggota.

8. Pengurus membuat data Anggota dan Kegiatan makam lalu memberikan laporan tersebut ke pihak Makam. 
9. Pihak Makam menerima laporan pembayaran yang sesuai dengan pemasukan dan pengeluaran yang ada dalam kegiatan makam.

Berikut ini merupakan tampilan Diagram Konteks sistem yang diusulkan:

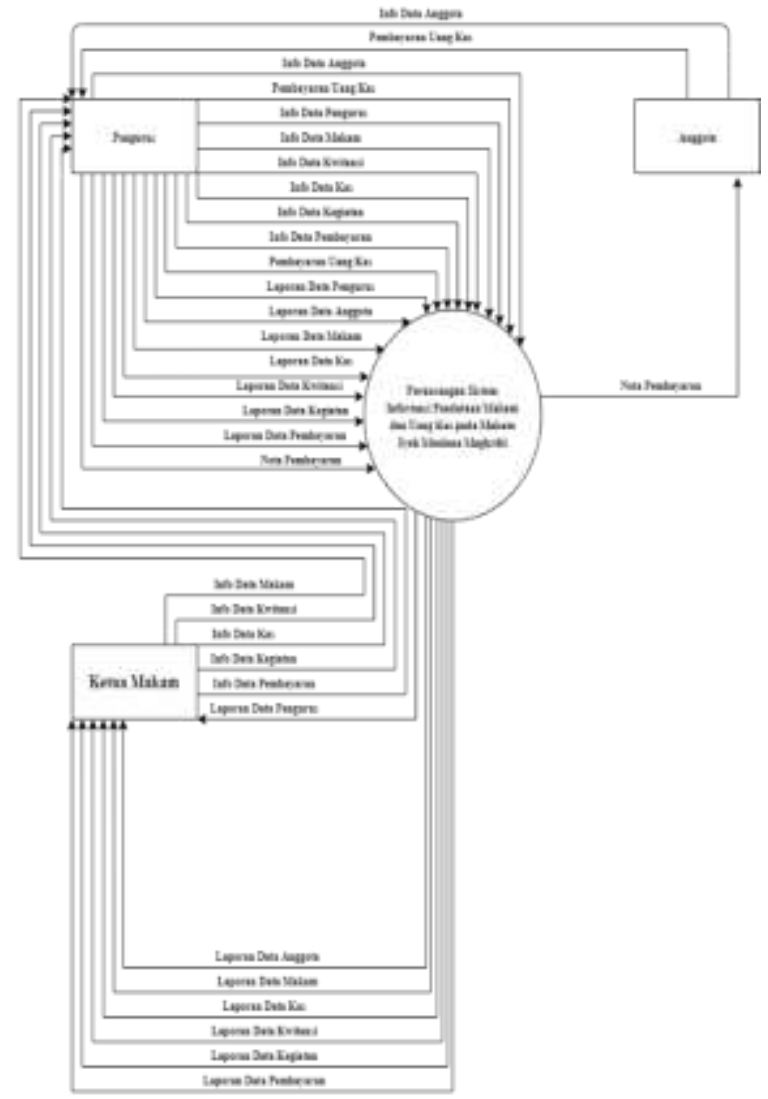

Gambar 2. Diagram Konteks

Berikut ini merupakan tampilan ERD sistem yang diusulkan:

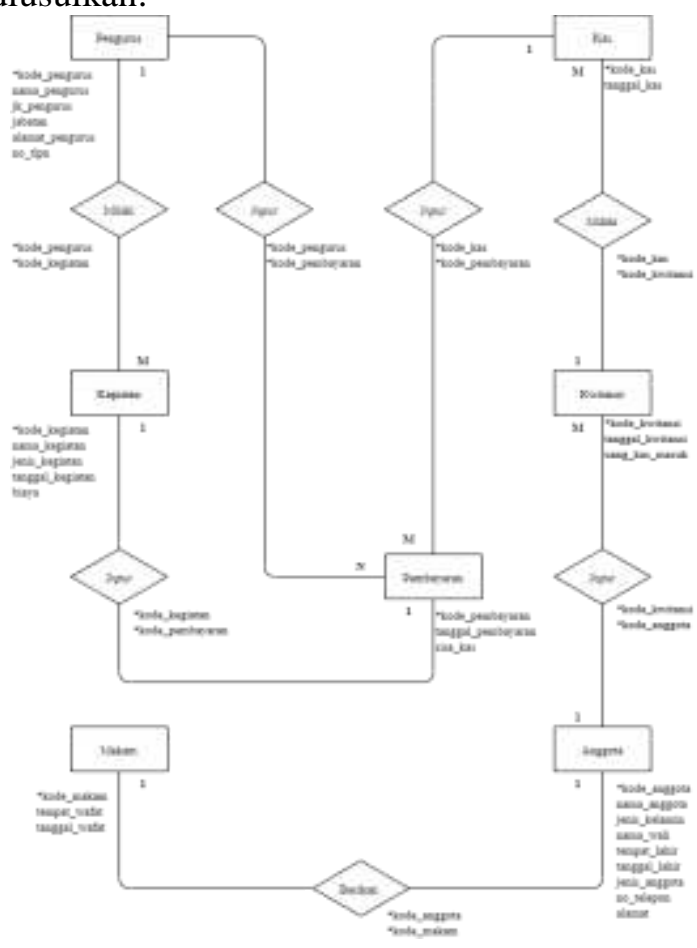

Gambar 3. ERD
Berikut ini merupakan tampilan Transformasi ERD sistem yang diusulkan:

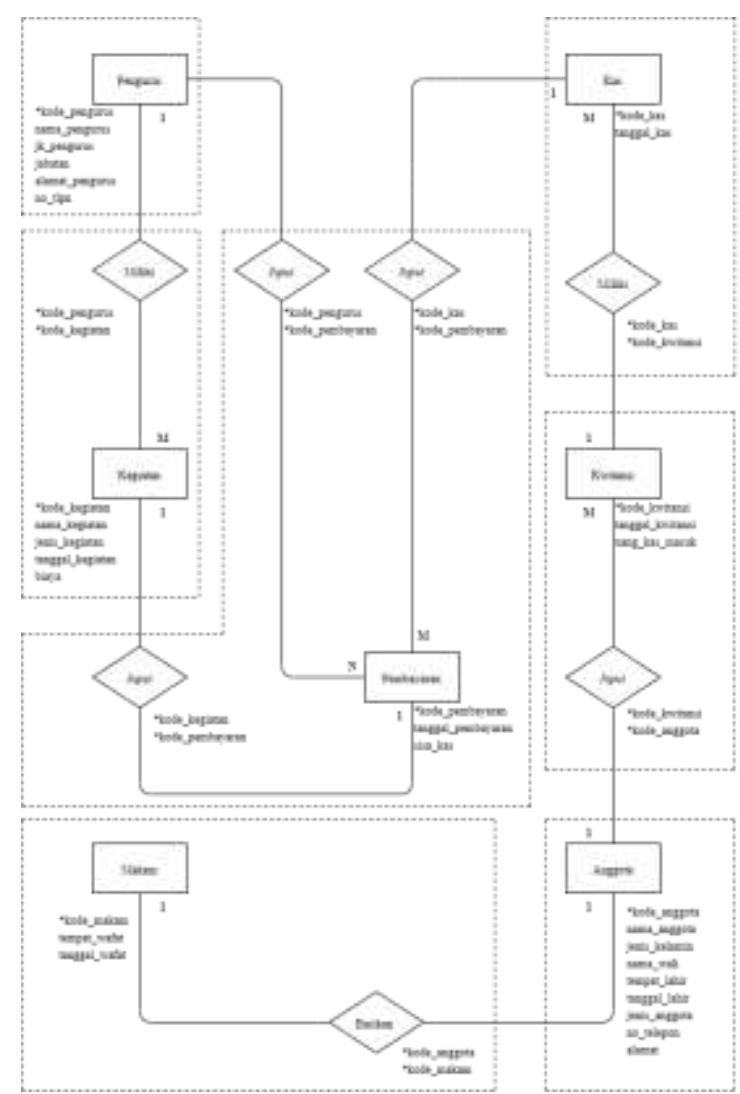

Gambar 4. Transformasi ERD

Berikut ini merupakan tampilan LRS sistem yang diusulkan:

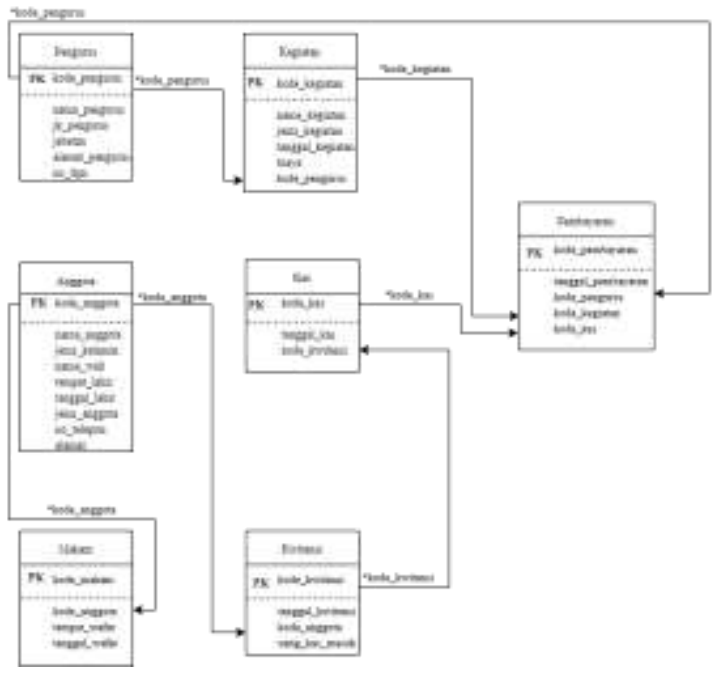

Gambar 5. LRS

Berikut ini merupakan tampilan layar dari aplikasi yang dihasilkan: 


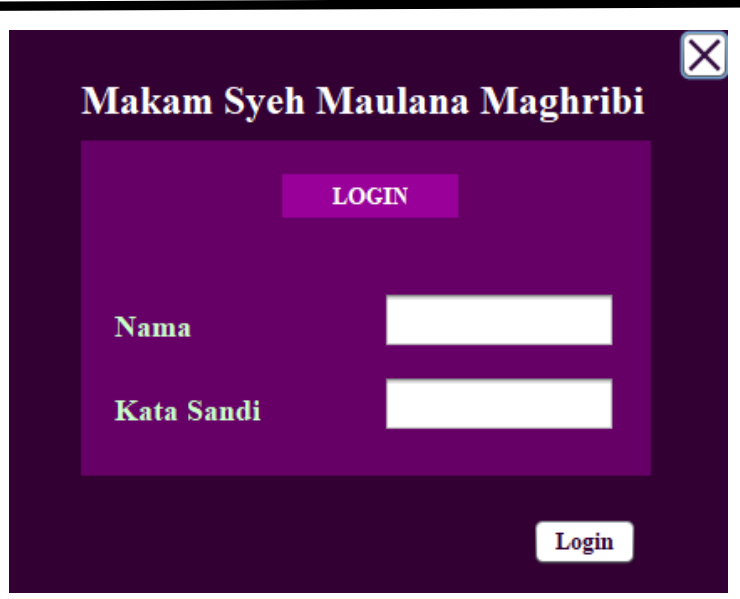

Gambar 6. Login

Rancangan ini terdapat pada awal program. Menu login digunakan sebagai kata kunci sebelum kita memasuki program utama. Agar tidak sembarangan orang yang dapat mengakses program ini. Sehingga kerahasiaannya tetap terjaga dengan baik.

Apabila pengguna dapat memasukkan nama pengguna dan kata sandi dengan tepat, maka menu beranda akan tampil dan program siap untuk dijalankan.

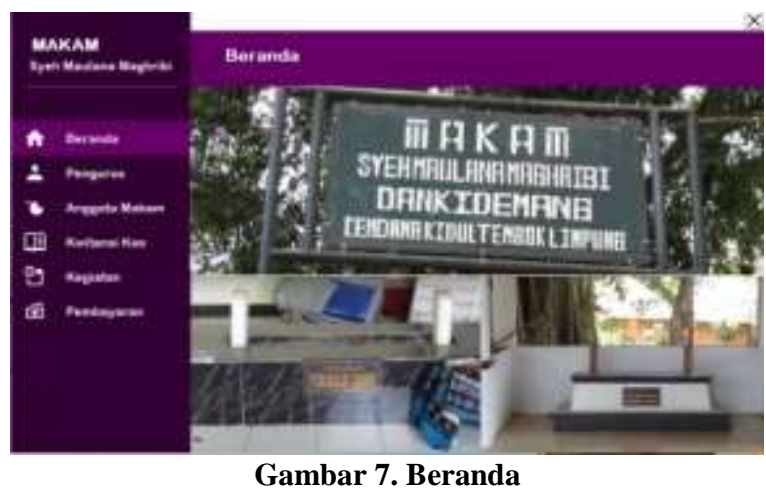

Layar ini menampilkan tampilan menu aplikasi sistem pendataan makam dan uang kas menggunakan java. Pada layar utama tersedia menu Data yang digunakan untuk menginput Pengurus, Anggota Makam, Kwitansi Kas, Kegiatan, dan Pembayaran. Di dalam menu Pengurus digunakan untuk menginput data Pengurus, menu Anggota Makam digunakan untuk menginput data Anggota dan menginput data Makam, menu Kwitansi Kas digunakan untuk menginput data Kwitansi dan menginput data Kas, menu Kegiatan digunakan untuk menginput data Kegiatan, dan menu Pembayaran digunakan untuk menginput data Pembayaran. Tanda X untuk keluar dari menu

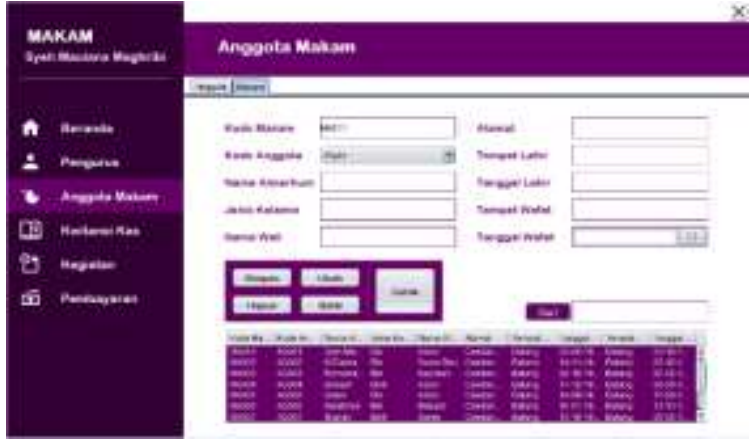

Gambar 8. Makam

Layar ini digunakan untuk menginput data Makam yang ada di Makam Syeh Maulana Maghribi. Tampilan menu terdapat tombol Simpan untuk melakukan input pendataan Makam, Hapus untuk menghapus data Makam, Ubah untuk mengubah data Makam, Batal untuk membatalkan penambahan data Makam, Tanda X untuk keluar dari menu, dan tombol Cetak untuk mencetak data Makam. Di dalam menu Makam terdapat toolbar Anggota yang digunakan untuk menginput data Anggota, menu Pengurus digunakan untuk menginput data Pengurus, menu Kwitansi Kas digunakan untuk menginput data Kwitansi dan menginput data Kas, menu Kegiatan digunakan untuk menginput data Kegiatan, dan menu Pembayaran digunakan untuk menginput data Pembayaran.

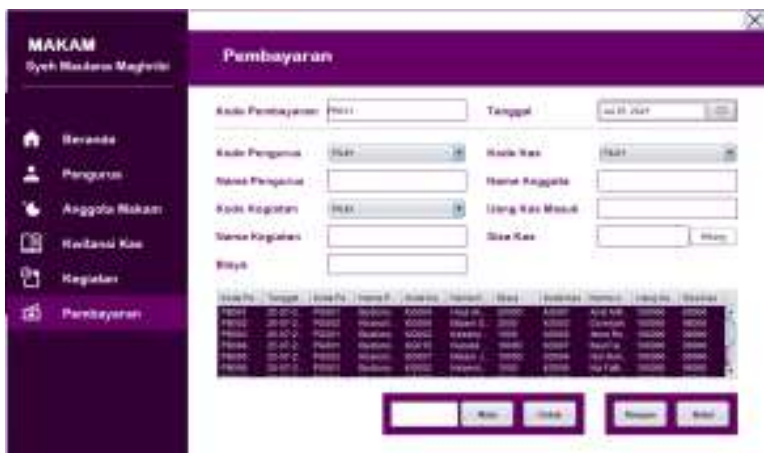

Gambar 9. Pembayaran

Layar ini digunakan untuk menginput data Pembayaran yang ada di Makam Syeh Maulana Maghribi. Tampilan menu terdapat tombol Simpan untuk melakukan input pendataan Pembayaran, Hapus untuk menghapus data Pembayaran, Ubah untuk mengubah data Pembayaran, Batal untuk membatalkan penambahan data Pembayaran, Tanda X untuk keluar dari menu, Tombol Cetak untuk mencetak data Pembayaran, dan Tombol Nota untuk mencetak Nota Pembayaran. Di dalam menu Pembayaran juga terdapat menu Pengurus digunakan untuk menginput data Pengurus, menu Anggota Makam digunakan untuk menginput 
data Anggota dan menginput data Makam, menu Kwitansi Kas digunakan untuk menginput data Kwitansi dan menginput data Kas, dan menu Kegiatan digunakan untuk menginput data Kegiatan.

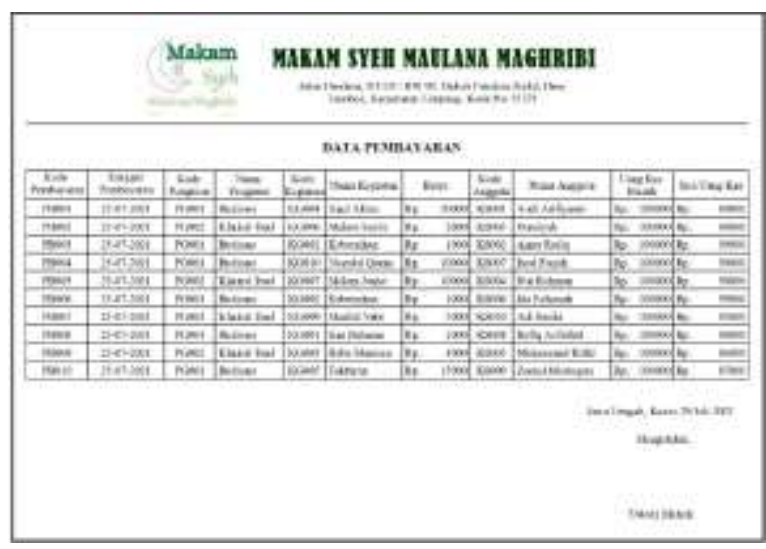

Gambar 10. Laporan Pembayaran

Layar ini menampilkan menu cetak laporan yang digunakan untuk mencetak laporan data Pembayaran. Tampilan ini dibuat dengan menggunakan jasper report, isinya merupakan data yang ditarik dari database untuk melihat laporan data Pembayaran.

\section{SIMPULAN DAN SARAN}

Dengan dibuatnya sistem pendataan makam dan uang kas yang terkomputerisasi ini semua kegiatan yang berhubungan dengan pendataan makam dan uang kas dapat berjalan dengan baik dan lancar. Dan dengan adanya aplikasi ini diharapkan akan mempermudah pendataan makam dan uang kas yang memerlukan kecepatan dan ketepatan informasi.

Kecepatan dan ketepatan hasil perancangan ini juga membutuhkan partisipasi aktif dari pemakai sistem, terutama kedisiplinan para pelaksana yang menangani secara langsung pada sistem yang dirancang. Dengan adanya jasa komputer sebagai alat bantu, penulis mempunyai simpulan dengan menggunakan sistem ini berdasarkan perumusan masalah sebagai berikut: Pendataan makam dan uang kas lebih efektif, cepat, dan terkonsep dalam pengolahan datanya. Pembuatan laporan pengeluaran dan pemasukan uang kas jadi lebih mudah. Mengelola, memproses, dan melihat hasil yang dibutuhkan pada setiap saat dengan cepat dan tepat. Data dapat tersimpan dengan aman dan pencarian data lebih mudah di cari.
Dengan diterapkannya pendataan makam dan uang kas berbasis java merupakan salah satu langkah maju dalam penerapan teknologi informasi. Sistem pendataan makam dan uang kas yang penulis buat hanya sebagai penunjang proses pendataan makam dan uang kas sebelumnya karena masih menggunakan metode konvensional.

Sejalan dengan sistem usulan yang penulis buat, maka demi tercapainya tujuan dan sasaran yang diharapkan, maka penulis dapat memberi saran sebagai berikut: Sistem informasi pendataan makam dan uang kas ini dapat dikembangkan kembali dalam penambahan database sesuai kebutuhan makam ke depannya. Sistem informasi pendataan makam dan uang kas ini haruslah didukung oleh sistem yang disiplin dan peraturan yang baik sesuai ketetapan bersama agar dapat berjalan dengan semestinya. Ketelitian merupakan salah satu hal utama dalam penggunaan sistem informasi ini, karena berhubungan dengan masyarakat setempat.

Adanya Sistem Informasi Pendataan Makam dan Uang Kas ini diharapkan mampu memberikan manfaat bagi Makam Syeh Maulana Maghribi. Penulis menyadari bahwa masih banyaknya kekurangan dalam pembuatan Sistem Informasi Pendataan Makam dan Uang Kas ini. Maka dari itu berharap sistem ini dapat dikembangkan lebih baik lagi dan mendapatkan saran yang lebih baik lagi untuk penulis. Demikian kesimpulan dan saran yang dapat penulis sampaikan, semoga skripsi ini dapat bermanfaat bagi penulis sendiri, dan pembaca.

\section{DAFTAR PUSTAKA}

Djam'an Satori, A. K. (2011). Metode Penelitian Kualitatif. Bandung. Alfabeta.

Fernandes, G. R., \& Lina, I. M. (2021). Penerapan Metode Fishbone Untuk Aplikasi Penjadwalan Aula Rt. Semnas Ristek (Seminar Nasional Riset Dan Inovasi Teknologi), 5(1).

Hasugian, H., \& Shidiq, A. N. (2012). Rancang bangun sistem informasi industri kreatif bidang penyewaan sarana olahraga. Semantik, 2(1).

Irwansyah, E., \& Moniaga, J. V. (2014). Pengantar Teknologi Informasi. Deepublish.

Raharjana, I. K. (2017). Pengembangan Sistem Informasi Menggunakan Metodologi Agile. Deepublish.

Romney, M. B., Steinbart, P. J., \& Cushing, B. E. 
(2015). Accounting information systems. Pearson Boston, MA.

Shihab, M. Q. (2020). al-Quran dan Maknanya. Lentera Hati.

Sukamto, \& Shalahuddin, M. (2015). Rekayasa Perangkat Lunak ( Terstruktur dan Berorientasi Objek) 2015. In Informatika Bandung.

Sutabri, T. (2012). Analisis sistem informasi.
Penerbit Andi.

Yuliani, E., Yunita, Y., \& Amalia, H. (2018). Rancang Bangun Sistem Informasi Akademik Sekolah Menengah Pertama Bakti Idhata. Bianglala Informatika, 6(1), 7-13. 